\title{
Friction stir processing of squeeze cast A356 with surface compacted graphene nanoplatelets (GNPs) for the synthesis of metal matrix composites
}

\author{
Ajay Kumar P., ${ }^{\text {a, }}$, H.C. Madhu ${ }^{\text {b, }}$, Abhishek Pariyar ${ }^{\mathrm{b}}$, Chandra S. Perugu ${ }^{\mathrm{d}}$, Satish V. Kailas ${ }^{\mathrm{b}}$, \\ Uma Garg ${ }^{\mathrm{e}}$, Pradeep Rohatgi ${ }^{\mathrm{a}}$
}

${ }^{a}$ Materials Science and Engineering Department, University of Wisconsin, Milwaukee, WI, 53211, USA

${ }^{\mathrm{b}}$ Mechanical Engineering Department, Indian Institute of Science, Bangalore, 560012, India

${ }^{\mathrm{c}}$ Mechanical Engineering Department, Siddaganga Institute of Technology, Tumkuru, 572103, India

${ }^{\mathrm{d}}$ Materials Engineering Department, Indian Institute of Science, Bangalore, 560012, India

${ }^{\mathrm{e}}$ Department of Physics, University of Wisconsin-Milwaukee, WI, 53211, USA

\section{A R T I C L E I N F O}

\section{Keywords:}

Metal-matrix composites (MMCs)

Graphene

Mechanical properties

Microstructures

Fractography

\begin{abstract}
A B S T R A C T
Friction stir processing (FSP) was applied to graphene nanoplatelets (GNPs) physically compacted on the surface of squeeze cast A356 alloy to incorporate GNPs within the matrix and to improve its mechanical properties. Squeeze casting resulted in finer size silicon and intermetallic compounds in cast microstructure, and subsequently FSP further refined the microstructure of squeeze cast A356 alloy, and GNP reinforced A356 alloy. The finer $\mathrm{Si}$ particles, intermetallics and graphene dispersed in the matrix increased the yield and ultimate tensile strength of FSP squeeze cast A356 alloy compared to the results reported in prior literature for FSP A356 alloy. Eutectic Si needles have been converted to fine spherical particles during FSP and were uniformly distributed within the nugget zone. The crystallite size of GNPs which were physically adhered to the surface of squeeze cast alloy prior to FSP decreased after FSP as a result of deformation. Thus, a combination of squeeze casting, and friction stir processing and incorporation of GNPs reinforcement in the A356 matrix is a promising route to further improve its mechanical properties.
\end{abstract}

\section{Introduction}

Development of novel techniques for manufacture of composites with low density and improved mechanical properties is receiving increasing attention in materials engineering. Carbon-based materials such as carbon fibers, carbon nanotubes (CNT) and graphene are promising candidates for reinforcing metal matrices, to achieve higher modulus strength, thermal and electrical properties. In this quest, carbon in the form of graphene as reinforcement has recently attracted attention due to its excellent mechanical and physical properties [1-5] as a particle reinforcement in metal matrix consisting aluminum and magnesium. Graphene is a 2D monolayer of carbon atoms which forms a hexagonal structure with $\mathrm{sp}^{2}$ hybridized orbitals. The conduction of electrons occurs through the $2 \mathrm{p}_{\mathrm{z}}$ orbitals that are perpendicular to the graphene plane. In addition to superior strength, graphene has exceptional electron mobility $\left(200000 \mathrm{~cm}^{2} \mathrm{~V}^{-1} \mathrm{~s}^{-1}\right)$, thermal conductivity $\left(\sim 6000 \mathrm{Wm}^{-1} \mathrm{~K}^{-1}\right)$, fracture strength (125 GPa), and Young's modulus $(\sim 1100 \mathrm{GPa})$ and is extremely light (density-1.06 $\left.\mathrm{g} \mathrm{cm}^{-3}\right)$ making it an ideal reinforcement material for metal where combination of strength, stiffness and conductivity are needed [6,7].

Aluminum matrix composites reinforced with GNPs have been synthesized by the powder metallurgy method, involving compaction, sintering, and hot extrusion; in certain studies, the tensile strength of the composite was increased by $62 \%$ as compared with the monolithic matrix. Uniform dispersion of graphene nanoparticles into a metal matrix was achieved by liquid state ultrasonic process and solid-state stirring [8]. The microhardness of $\mathrm{Al}-\mathrm{Mg}$ composites reinforced with graphene nanoplatelets (GNPs) was increased by $78 \%$ by using a high-power ultrasonic probe to disperse graphene in magnesium alloy melts, followed by friction stir processing [9]. In another study, no aluminum carbide formation was observed using powder metallurgy processing [10]. Aluminum reinforced with $0.58 \mathrm{wt} \%$ graphene prepared by cryo-milling increased the strength and ductility as compared with monolithic aluminum. By incorporating 1 at. \% of GNP in aluminum, the tensile strength and ductility improved by $8.3 \%$ [11]. Addition of $0.3 \mathrm{wt} \%$ GNPs increased the tensile strength by $62 \%$ of

\footnotetext{
* Corresponding author.

E-mail address: Ajaykumarmech85@gmail.com (P. Ajay Kumar).
} 

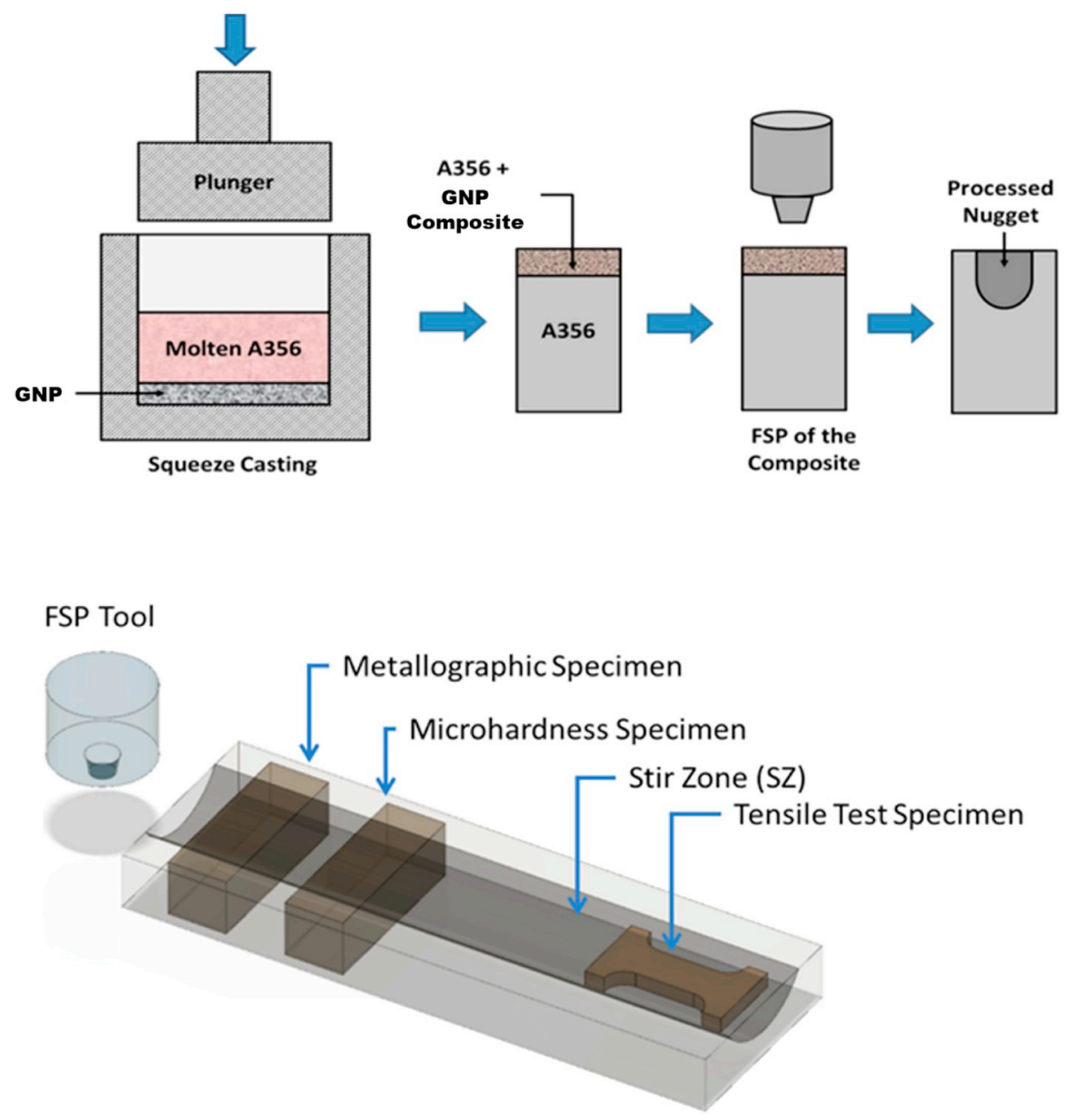

Fig. 1. Schematic illustration of the FSPed plate and specimen location on the plate.

$\mathrm{Al} / \mathrm{GNP}$ composite [12] and $0.7 \mathrm{vol} \%$ of few-layer graphene (FLG) increased the composite strength by $440 \mathrm{MPa}$ [13]. Results showed a $15 \%$ increment in thermal conductivity of Al-graphene metal matrix composites (MMC) and increased ductility by $10 \%$ [14]. The measured properties of graphene reinforced metal matrix composites show considerable scatter from one investigator to the next, and the properties are very much below theoretically predicted properties. There is relatively little understanding of reasons (a) for the exceptional improvements in properties in certain experiments reported to date, (b) the large scatter in properties (c) the decrease in properties above $1-2 \% \mathrm{wt} \%$ of nanosized reinforcements and (d) the fundamental issues related to solidification and processing of these materials, including the dispersion of nanosized particles, nanotubes, and flakes in metallic melts [8,15-27]. It has not been possible to disperse more than $5 \%$ graphene and achieve a uniform distribution of graphene in the matrix using either powder metallurgy or liquid metallurgy techniques. Therefore, in this paper FSP has been explored as a method to incorporate graphene adhering on the surface, into the metal matrix.

As-cast heat-treatable alloys like A356 are one of the most widely used alloys in the aircraft and automotive industries [28] due to the fact that they can be strengthened by artificial aging [29-31]. However, the mechanical properties of A356 are significantly affected by microstructural features such as secondary dendrite arm spacing (SDAS) [32, 33], microporosity [34,35], intermetallics [36], eutectic silicon particles [34-37], and heat treatments [31,37]. The as-cast microstructure of A356 (Fig. 2) is usually characterized by a coarse dendritic structure, nonuniformly distributed $\mathrm{Si}$ particles in the interdendritic region and porosity [32-35,38-41]. These microstructural features limit the mechanical properties of cast alloys, in terms of toughness and fatigue resistance. To overcome some of these issues with sand casting, Friction Stir Processing (FSP) of sand cast A356 has been explored [42]. During FSP process, a rotating tool with a probe severely deforms to the work piece by frictional heating, due to which agglomerates of particles, intermetallic compound particles and the dendritic structures are broken down and refined, and porosity is refined or closed, thereby improving mechanical properties [43].

FSP has emerged as a viable technique for fabricating metal matrix composites [44,45]. During friction stir processing of metal matrix composites, the material undergoes intense plastic deformation resulting in the mixing of ceramic particles and the metal. FSP also results in significant refinement of grains [46]. FSP has also been used to homogenize the microstructure of aluminum alloys and improved fatigue strength [47]. FSP technology has also been used to refine the microstructure of cast aluminum alloys, and particle-reinforced composites, fabricate a surface/bulk composite of $\mathrm{Al}-\mathrm{SiC}$ on an aluminum substrate [48-51]. Friction stir surfacing of cast Al-Si alloy with boron carbide and molybdenum disulphide powders [50,52] has been done and ultra-fine-grained $\mathrm{Cu} / \mathrm{SiC}$ composites $[53,54]$ have been produced by FSP. The surface structure of sand cast eutectic Al-12Si alloy has been modified by FSP to improve its microstructural, mechanical and tribological properties [55]. Furthermore, recently a new multi-layer graphene reinforced aluminum composites have been synthesized using exfoliation of low-cost graphite into graphene via Friction Stir Processing (FSP) with a two-fold increase in strength, which opens new possibilities towards efficient and scalable manufacturing of metal matrix nanocomposites [56], containing graphene. 

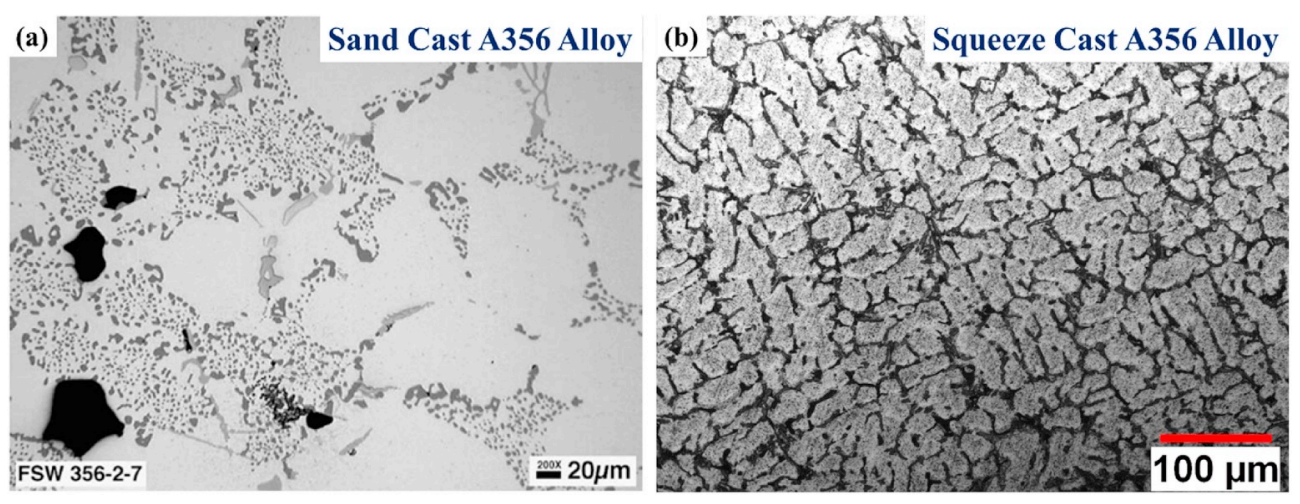

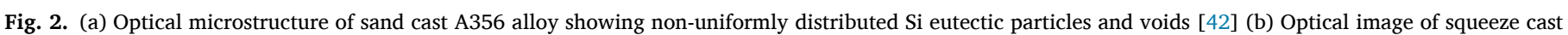
A356 alloy showing fine grains and Si eutectic particles at the grain boundary.

In this study, we have attempted to enhance the mechanical properties of A356 by using a combination of squeeze casting, and friction stir processing to refine the microstructure of the matrix, and also incorporate and disperse GNPs within the matrix, which were physically adhering to the squeeze cast surface into the matrix. We report the effects of FSP on the microstructure of the matrix and its mechanical properties, and the incorporation of graphene in the matrix. We also report the breakdown of the dendritic structures and refinement and redistribution of intermetallic particles in the matrix as a result of FSP to improve strength and ductility. Hence, the current study attempts to combine the applications of a combination of squeeze casting and FSP to produce GNPs reinforced A356 matrix.

\section{Experimental procedure}

A356 alloy with a nominal composition of 7.0Si-0.3 Mg-0.2Cu bal. Al (wt\%) was used as a matrix material with M5 grade graphene nanoplatelets (GNPs) as reinforcement material compacted on the surface during squeeze casting. A squeeze cast plate with GNPs physically adhering to the surface was produced by a squeeze casting process. The molten metal is poured into the bottom half of a preheated die where a loose bed of GNP powder particles were spread on the surface of the bottom plate of the mold. As soon as the metal is poured, the upper half of the die closes and starts applying pressure during the solidification process. The extent of pressure applied is significantly less than that in forging. The high pressure and the close contact of molten alloy with the metal die surface and powder resulted in a discontinuous compacted coating of GNPs physically adhering (but not incorporated in the matrix) to the surface of squeeze cast A356 alloy. These surface coated samples were further processed by multi-pass FSP process.

The FSP experiments were carried out in a five axis friction stir welding machine (BiSS-ITW, Bangalore, India). An HSS tool with a frustum-shaped threaded pin, $6 \mathrm{~mm}$ top diameter, $4 \mathrm{~mm}$ bottom diameter, rounded end and $15 \mathrm{~mm}$ diameter flat shoulder with a chamfered edge was used. The tool was tilted at $2^{\circ}$. The tool was rotated in a counter-clockwise direction at $1200 \mathrm{rpm}$ and traversed with a speed of $15 \mathrm{~mm} / \mathrm{min}$. Six multi passes were carried out.

The samples for microstructural characterization and mechanical
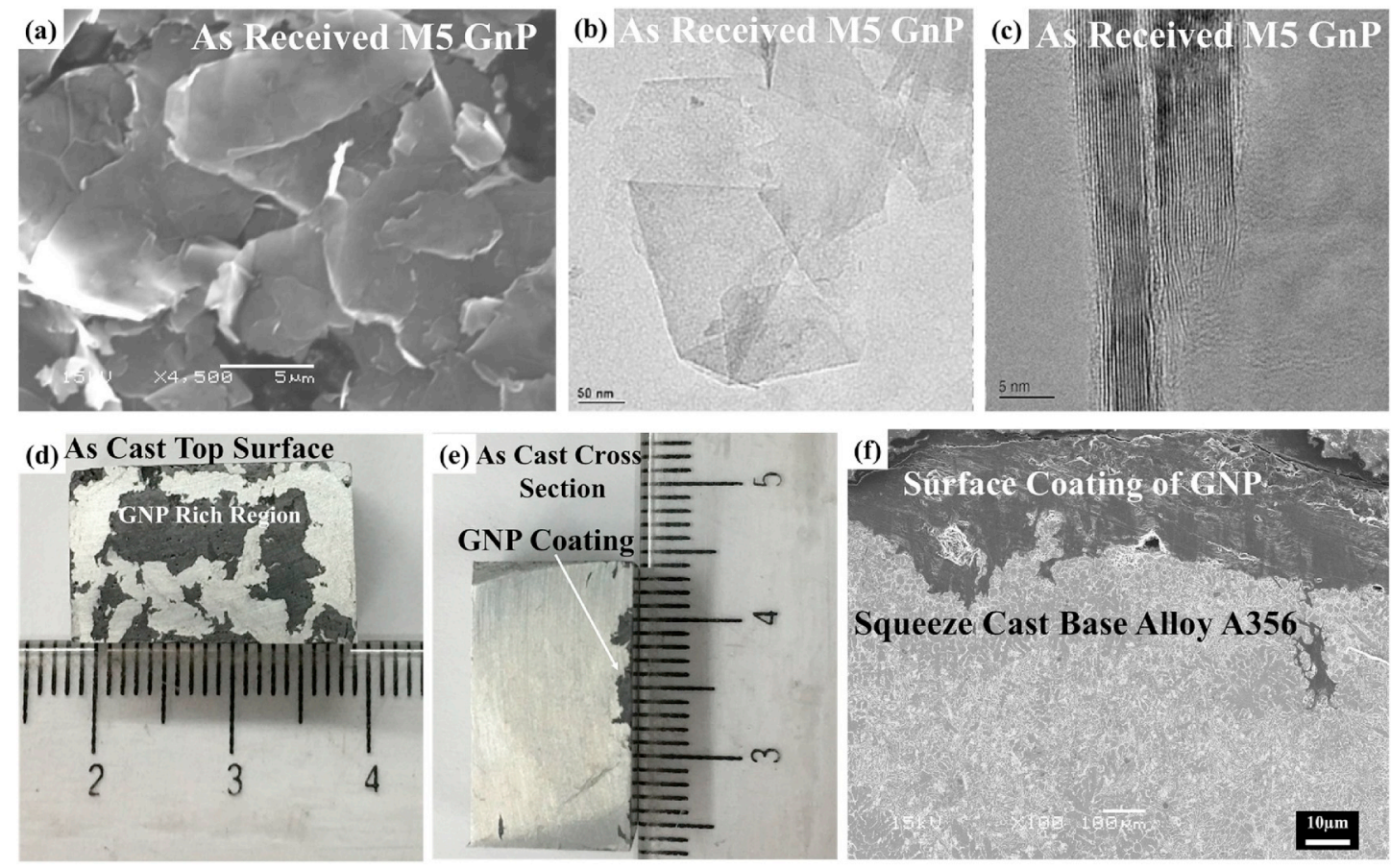

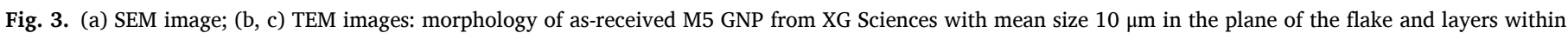

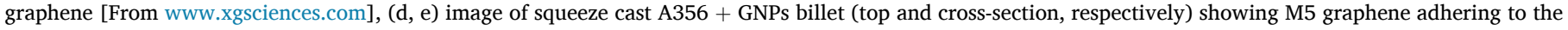
surface of squeeze cast A356 alloy (f) SEM image of A356 surface coated with GNPs by squeeze casting before FSP. 

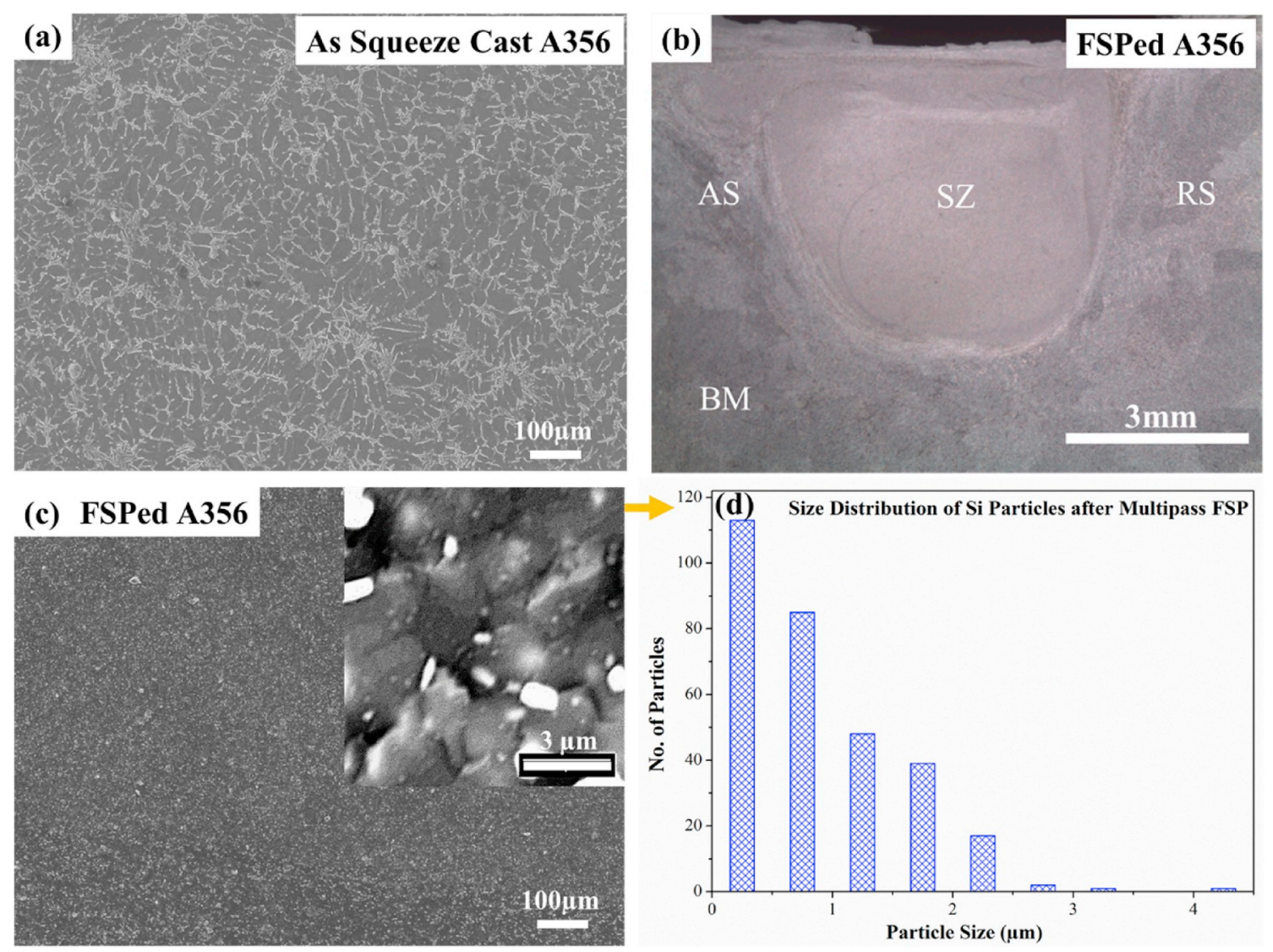

Fig. 4. (a) SEM image of non-FSP region showing $\alpha$-aluminum dendrites of $50 \mu \mathrm{m}$ size and Si needles of $\sim 20 \mu \mathrm{m}$ in the interdendritic region (b) stereo macrograph of the FSP zone of A356 alloy (c) fine spherical Si particles around $200 \mathrm{~nm}$ after multi-pass FSP (d) size distribution of Si particles size after FSP.

testing were cut from the friction stir processed zone using a wire Electro-Discharge Machining (EDM). The samples from as-cast A356, transverse sections of the FSP A356 and composite were polished using standard methods and characterized using an SEM (Tescan Vega 3 and Jeol IT300). The FSP composite from the nugget region was dissolved in $\mathrm{NaOH}$ solution. The residue left after dissolution was washed with deionized water to remove $\mathrm{NaOH}$. The cleaned residue was drop-cast on a Si wafer to conduct Raman analysis. Dog-bone-shaped specimens with the gauge sections of $6 \mathrm{~mm} \times 2 \mathrm{~mm} \times 1 \mathrm{~mm}$ were taken from the top region of friction stir processed material for the tensile tests (Fig. 1). The tensile axis of the specimen was oriented parallel to the processed direction of the plate subjected to friction stir processing. The tensile tests were performed using an Instron-5976 Uniaxial Testing Machine at a strain rate of $10^{-3} \mathrm{~s}^{-1}$. At least three tests were conducted, and the average of these results was considered as the mean strength and ductility values.

\section{Results and discussions}

\subsection{Micro and macrostructure before friction stir processing}

Fig. 2(a) shows the microstructure of sand cast A356 alloy with grain size more than $100 \mu \mathrm{m}$ and voids and the coarse interdendritic Al-Si eutectic [42]. In contrast, the squeeze cast A356 matrix consists of dendrites of primary aluminum $50-60 \mu \mathrm{m}$ in size and inter-dendritic irregular Al-Si eutectic regions (Fig. 2(b)). The needle shaped Si particles are present as part of $\mathrm{Al}-\mathrm{Si}$ eutectic in the interdendritic region between $\alpha$-aluminum dendrites. Further, most $\mathrm{Si}$ particles exhibited a fibrous needle shape morphology. The squeeze-cast A356 Al plates showed a sound microstructure with relatively fewer pores $1-2 \mu \mathrm{m}$ in diameter between the dendrites [57]. The volume fraction of $\alpha$-Al is greater than the Al-Si eutectic structure in A356 alloy [58]. Fig. 3(a-c) shows the morphology of GNPs powder as received from the supplier of average particle size $\sim 10 \mu \mathrm{m}$ parallel to the plane of flakes. Fig. 3(d) and (e) show the SEM image of the surface of squeeze cast plate to which compacted GNPs flakes were physically adhered. The top surface and cross-sections show that the layer of graphene physically adhered to squeeze cast aluminum was not continuous and also was not of uniform composition. Fig. 3(f) shows the coarse microstructure of squeeze cast A356 alloy to which a dark layer of GNPs is physically adhered before FSP. Further, it is seen that GNPs are compacted on the surface of squeeze cast $\mathrm{Al}-\mathrm{Si}$ plate.

\subsection{Microstructure after friction stir processing}

Fig. 4(a) shows the microstructure of as squeeze cast A356 alloy. The coarse dendritic structure and the porosity during casting of A356 have a detrimental effect on its mechanical properties. The coarse dendritic structure and needle shaped $\mathrm{Si}$ are responsible for lower toughness and fatigue resistance. Earlier studies have shown that the deformation of the dendritic structure can enhance the strength and ductility of the A356 alloy [57,60]. Fig. 4(b) shows the stereo macrograph of the friction stir processed zone. It is observed that the friction stir processed nugget zone is $U$ shaped basin with a wide top. It is evident from the micrographs in Fig. 4(c-d) that the dendritic structure of the as squeeze cast A356 is no longer present in the matrix after FSP, and eutectic Si needles originally of $\sim 10-20 \mu \mathrm{m}$ size have been converted to finer spherical particles, around $\sim 200 \mathrm{~nm}$ size, which are uniformly distributed within the FSPed zone. The ductility of FSPed materials is higher because of the refinement in grain size as well as a reduction in the size of intermetallic compounds. These causes lead to an increase in ductility override the decrease in ductility due to work hardening. 

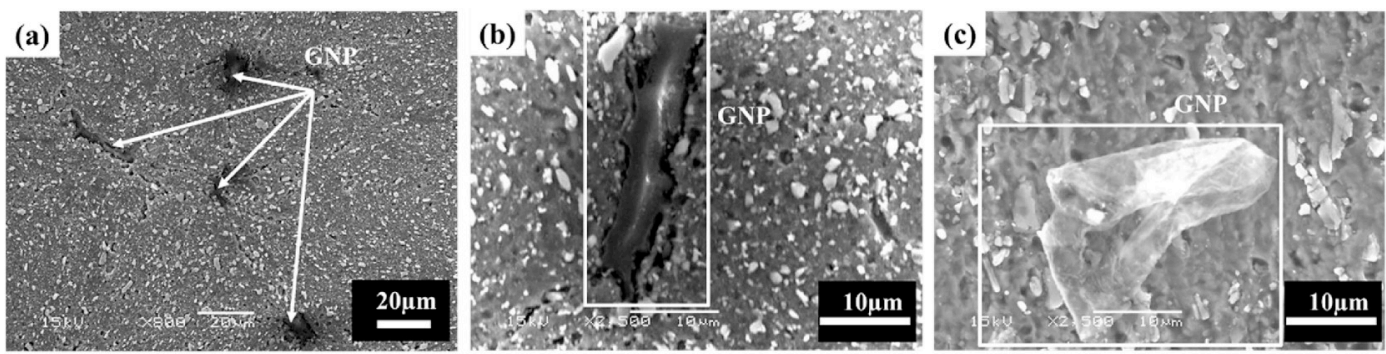

Fig. 5. (a) SEM micrograph of the composite showing GNP flakes embedded in the FSP matrix, (b) \& (c) show an enlarged view of the individual graphene flakes embedded in the matrix at higher magnification after six multi-pass FSP.
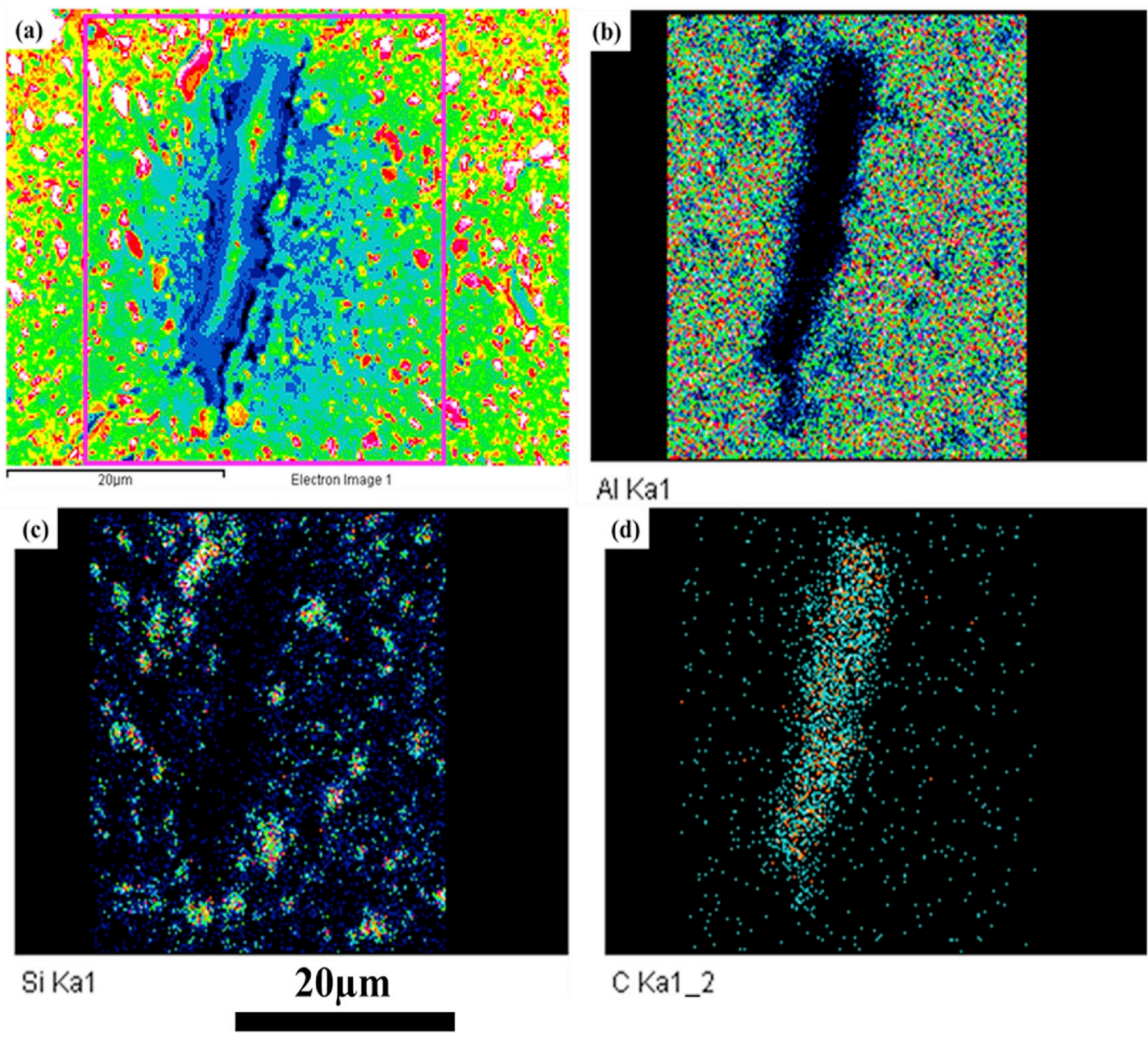

CKa1_2

Fig. 6. SEM-EDS mapping shows (a) the GNP flake embedded in matrix (b-e) color mapping of elements Al, Si and C after six multi-pass FSP. (For interpretation of the references to color in this figure legend, the reader is referred to the Web version of this article.)

The GNP particles can be observed in the SEM image of the friction stir processed zone in Fig. 5(a). Fig. 5(b) and (c) show the enlarged view of individual GNP at higher magnification. Fig. 5(b) and (c) show that GNPs are encapsulated and dispersed in the matrix, instead of adhering to the surface. GNP particles, which exhibit curvature in some cases, are observed in the FSPed region of the aluminum matrix. This may be attributed to the extremely large ratio of lateral dimension to a thickness of GNP flakes and the complex flow during FSP [59].

Fig. 6, and Fig. 7 show the elemental mapping (Energy Dispersive Spectroscopy (EDS)) of GNPs dispersed in the matrix shown in Fig. 5(b) and 5(c) respectively. In the elemental mapping of FSPed zone (Fig. 6, and Fig. 7), four major elements $\mathrm{Al}, \mathrm{C}, \mathrm{Si}$, and $\mathrm{Cu}$ are present respectively. The dark appearing GNP flakes (Fig. 5(a)) encapsulated in the metal matrix after FSP are visible in carbon mapping micrograph of Fig. 6, and Fig. 7.

\subsection{Raman spectroscopy analysis}

Raman spectroscopy was performed using Renishaw Inc. $1000 \mathrm{~B}$ spectrometer with Helium-Neon laser of wavelength $633 \mathrm{~nm}$ and $532 \mathrm{~nm}$. Fig. 8 shows the Raman spectra of the FSPed A356 containing encapsulated GNPs in the matrix. The red curve shows the Raman spectrum of as-received GNPs collected using $633 \mathrm{~nm}$ laser in Fig. 8(a). In as-received GNPs, D band, G band, and the 2D band appear at $1300 \mathrm{~cm}^{-1}, 1600 \mathrm{~cm}^{-1}$, and $2650 \mathrm{~cm}^{-1}$ respectively. The presence of $\mathrm{D}$ peak in the spectrum indicates the presence of defects in the crystal 

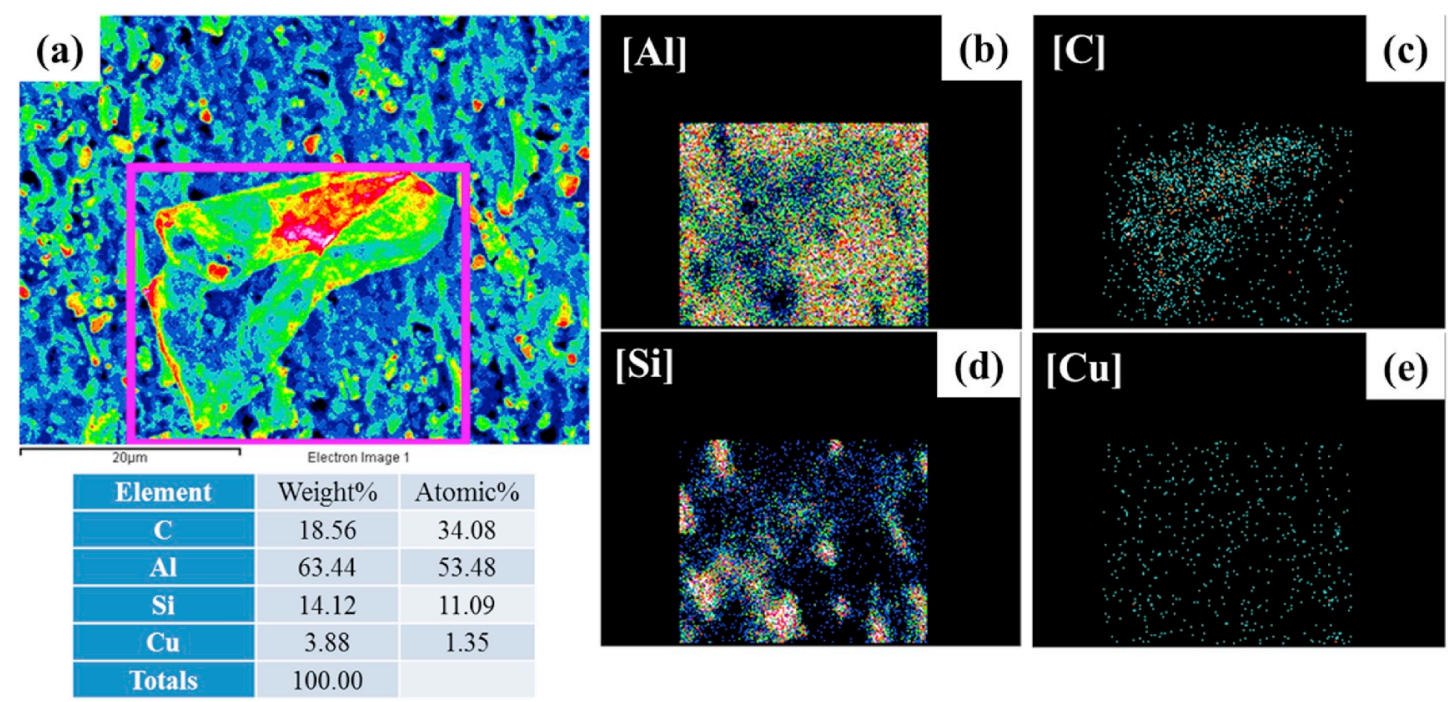

Fig. 7. SEM-EDS mapping shows (a) GNP embedded in the matrix (b-e) color mapping of elements $\mathrm{Al}$, Si and C after six multi-pass FSP. (For interpretation of the references to color in this figure legend, the reader is referred to the Web version of this article.)
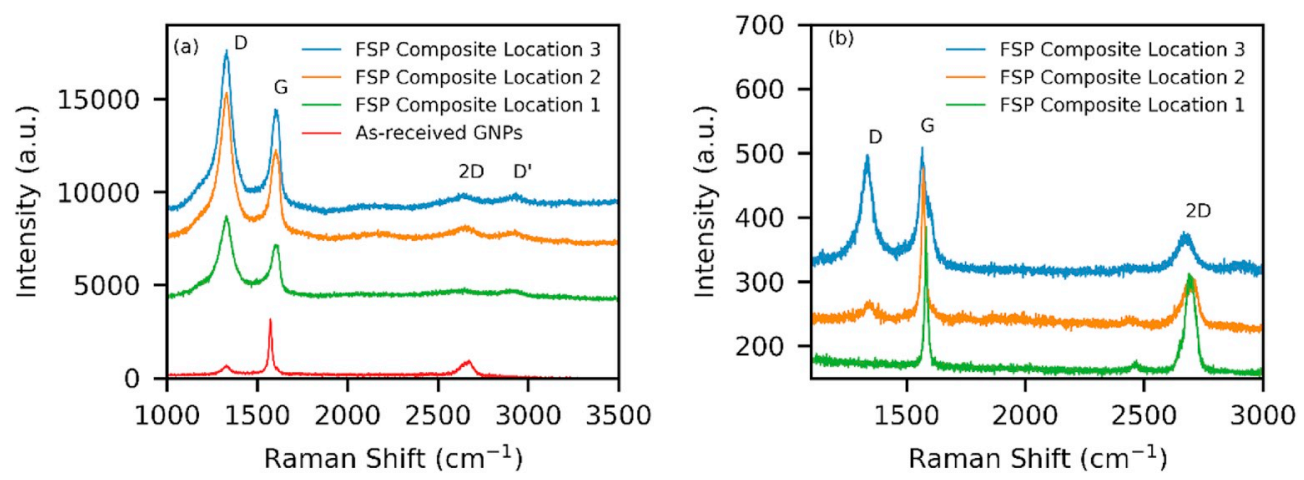

Fig. 8. (a) Raman spectrum of as-received GNPs and FSPed composite at several spots using $633 \mathrm{~nm}$ laser (b) Raman spectra of GNPs obtained after dissolving the FSPed composite in $\mathrm{NaOH}$ solution using $532 \mathrm{~nm}$ laser.

lattice [61]. Defects can result in the crystal lattice due to the disorder along the $\mathrm{c}$ axis, change of hybridization of carbon atoms and vacancies. Defects in GNP lattice break down hexagonal symmetry of the $\mathrm{sp}^{2}$ hybridized layers and modify the optical selection rules for the lattice vibrational modes observed in Raman scattering [62]. The Raman spectrum was also collected at different locations after FSP in the composite region. As shown in Fig. 8(a), the intensity of 2D peak decreases, and the intensity of D peak increases significantly after FSP. The defects in the graphene lattice have increased as the intensity of D peak increases after FSP. According to Kaniyoor et al. a high number of defects in the lattice can suppress the 2D band [63]. One more defect peak D' appears at $3000 \mathrm{~cm}^{-1}$ after FSP. Fig. 8(b) shows the Raman spectrum collected at a different spot using $532 \mathrm{~nm}$ wavelength laser. At FSP location 1 in Fig. 8(b), the intensity ratio $\mathrm{I}_{2 \mathrm{D}} / \mathrm{I}_{\mathrm{G}}$ is around 0.72 , which suggests the further exfoliation of GNPs [64] during FSP. The ratio of the $\mathrm{D}$ and $\mathrm{G}$ band intensities $\left(\mathrm{I}_{\mathrm{D}} / \mathrm{I}_{\mathrm{G}}\right)$ is inversely proportional to the in-plane crystallite size $\mathrm{L}_{\mathrm{a}}$ [65]. As shown in Fig. 8(a) and (b), the ratio $\mathrm{I}_{\mathrm{D}} / \mathrm{I}_{\mathrm{G}}$ increased after FSP. This implies that the in-plane crystallite size decreased after FSP. The in-plane crystallite size $\left(L_{a}\right)$ from the Raman spectra taken at various locations of the graphene samples is calculated using the general equation $\mathrm{L}_{\mathrm{a}}=\left(2.4 \times 10^{-10}\right) \lambda_{\text {laser }}^{4}\left(\mathrm{I}_{\mathrm{D}} / \mathrm{I}_{\mathrm{G}}\right)^{-1}$, where $\lambda$ is the wavelength of the laser light in nm unit [66]. The defect density $n_{\mathrm{D}}$ $\left(\mathrm{cm}^{-2}\right)=10^{14} /\left(\pi L_{\mathrm{a}}^{2}\right)$ is given as: $n_{\mathrm{D}}\left(\mathrm{cm}^{-2}\right)=\frac{1.8 \times 10^{22}}{\lambda_{L}^{4}}\left(\frac{I_{D}}{I_{G}}\right)$ [67]. The crystallite sizes and defect densities obtained at different spots using
Table 1

In-plane crystallite sizes of GNPs calculated at different spots in the FSP region and as-received GNPs using Raman spectrum $\left(\lambda_{\text {laser }}=633 \mathrm{~nm} \& \lambda_{\text {laser }}=532 \mathrm{~nm}\right)$.

\begin{tabular}{llll}
\hline$\lambda_{\text {laser }}=633 \mathrm{~nm}$ & $\mathrm{I}_{\mathrm{G}} / \mathrm{I}_{\mathrm{D}}$ & $\mathrm{L}_{\mathrm{a}}(\mathrm{nm})$ (Crystal Size) & $n_{\mathrm{D}}\left(\mathrm{cm}^{-2}\right)$ (Defect Density) \\
\hline As-received GNPs & 5 & 192 & $22 \times 10^{9}$ \\
FSP Location 1 & 0.82 & 31 & $136 \times 10^{9}$ \\
FSP Location 2 & 0.78 & 30 & $143 \times 10^{9}$ \\
FSP Location 3 & 0.81 & 31 & $138 \times 10^{9}$ \\
$\lambda_{\text {laser }}=\mathbf{5 3 2} \mathrm{nm}$ & & & $124 \times 10^{9}$ \\
FSP Location 2 & 1.80 & 34.66 & $218 \times 10^{9}$ \\
FSP Location 3 & 1.03 & 19.96 &
\end{tabular}

these equations are given in Table 1 for laser wavelengths $633 \mathrm{~nm}$ and $532 \mathrm{~nm}$, respectively.

\subsection{X-ray diffraction analysis}

XRD was performed using Bruker D8 XRD diffractometer with nickelfiltered $\mathrm{Cu}-\mathrm{K} \alpha$ radiation $(\lambda=1.54 \AA$ ) as the X-ray source. XRD diffractograms of A356 base metal, A356-GNP composite after FSP and asreceived GNPs are shown in Fig. 9. All the major peaks of aluminum are present in $\mathrm{A} 356$ base metal and A356-GNP composite after FSP. Si and $\mathrm{Al}_{2} \mathrm{Cu}$ peaks can also be seen. $\mathrm{Al}_{2} \mathrm{Cu}$ is observed in the specimen because 


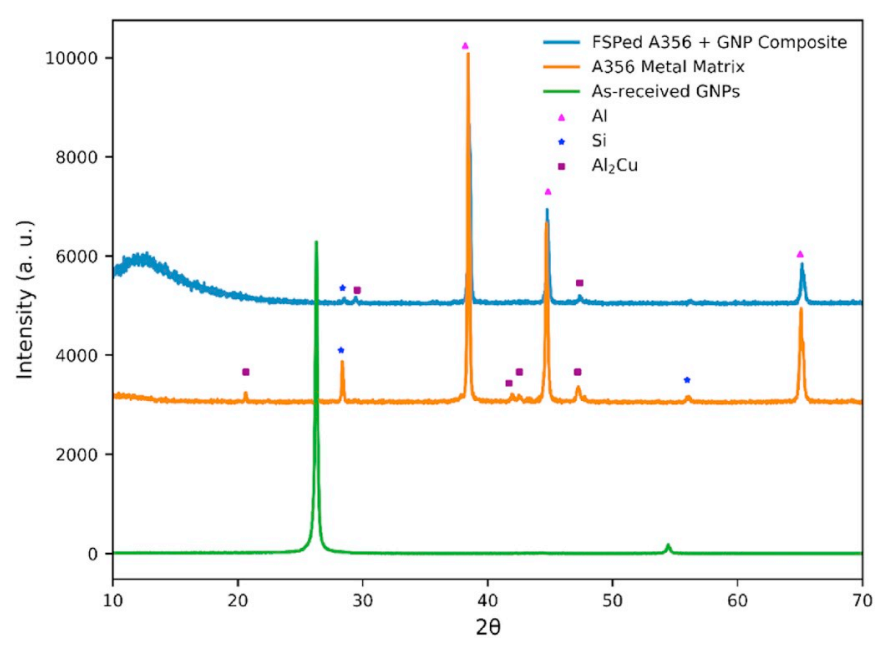

Fig. 9. The X-ray diffractogram of A356 base metal, A356-GNP composite after FSP and as-received GNPs.

of the presence of $0.2 \% \mathrm{Cu}$ in the $\mathrm{A} 356$ base metal matrix.

\subsection{Transmission electron microscopy (TEM) analysis}

TEM observations indicated that after FSP, the GNP flakes are reinforced and encapsulated in the Al matrix. The interface clearly shows that the $\mathrm{Al}$ matrix and GNP are in close contact without any micro voids as shown in Fig. 10(a). The TEM bright field (BF) images also show nano size particles of $\mathrm{Si}$ and $\mathrm{Al}_{2} \mathrm{Cu}$ distributed in the matrix (Fig. 10(b) and (c)).

\subsection{Mechanical properties of FSPed (A356 + GNP) composites}

Fig. 11 shows a histogram plot of the strength and elongation for the as squeeze-cast A356 and A356 reinforced with GNPs and Fig. 12(a) shows their true stress-strain curves. From Fig. 11, it is observed that the base material before FSP, yield strength is $120 \pm 20 \mathrm{MPa}$, UTS is $238 \pm 15 \mathrm{MPa}$ and percentage elongation is $7.6 \pm 2 \%$. For FSPed A356 reinforced with GNPs, the yield strength, UTS, and \% elongation are $190 \pm 13 \mathrm{MPa}, 357 \pm 3 \mathrm{MPa}$, and $12 \pm 1 \%$ respectively. Ma et al. performed FSP of as sand cast A356 and reported a yield strength increase by $23 \%$, UTS by $51 \%$ and ductility from 3 to $34 \%$ respectively after two passes including other researchers [68-71]. The present study reports increase in the yield strength by $58.3 \%$, UTS by $50 \%$ and ductility from $7.6 \%$ to $12 \%$ where FSPed A356 is reinforced with GNPs. A comparison of the mechanical properties of FSP A356 + graphene with previous research work is shown in Table 2 . This proves that such a substantial increase in the yield strength, UTS and \% elongation observed in the present study are mainly due to the refinement of microstructure due to squeeze casting followed by FSP as well as due to the reinforcement of GNPs in the matrix.

The analysis of the effect of GNPs and FSP on the work-hardening rate was done by using a differential form of the Voces equation $\theta=\theta_{0}\left(1-\sigma / \sigma_{\mathrm{s}}\right)$. This, in turn, was used to plot the Kocks-Mecking curves, where $\theta$ is the hardening rate, $\theta_{0}$ is the work-hardening limit, $\sigma$ is the current flow stress and $\sigma_{\mathrm{s}}$ is the saturation stress [72]. It can be observed from Fig. 12 (b) that the strain-hardening rate of the as-squeeze cast A356 and A356 reinforced with GNPs are $5554 \mathrm{MPa}$ and $9474 \mathrm{MPa}$, respectively. Both the base material and the composite show stage III hardening.

\subsection{Fractography analysis}

Fig. 13 shows the fractographs of the fractured surface of the FSPed A356-GNP composite. As can be seen, the fractured surface of the composite is markedly finer compared to the as cast base metal. The fractured surface of the composite also shows dimpled morphology, indicative of a more ductile fracture (Fig. 13 (a)). Furthermore, GNPs were frequently observed on the fractured surface (Fig. 13 (b)). To confirm the flakes observed in the fractured surface were indeed GNPs, Energy Dispersive Spectroscopy (EDS) mapping of the fractured surface was performed as shown in Fig. 14. This further confirms that GNP flakes which were originally only physically adhered to the squeeze cast surface before FSP were embedded in the matrix during FSP process.

\section{Conclusions}

1) Friction Stir Processing of squeeze cast A356 alloy with refined microstructure resulted in finer nanosized silicon and intermetallic

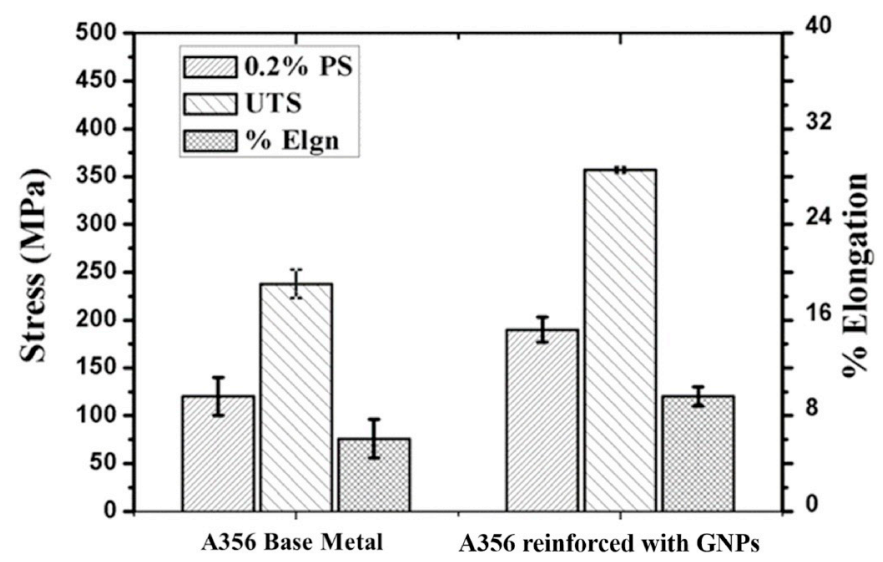

Fig. 11. Shows of yield strength, UTS and percentage elongation of base metal A356 before FSP and A356-GNP composite after FSP.
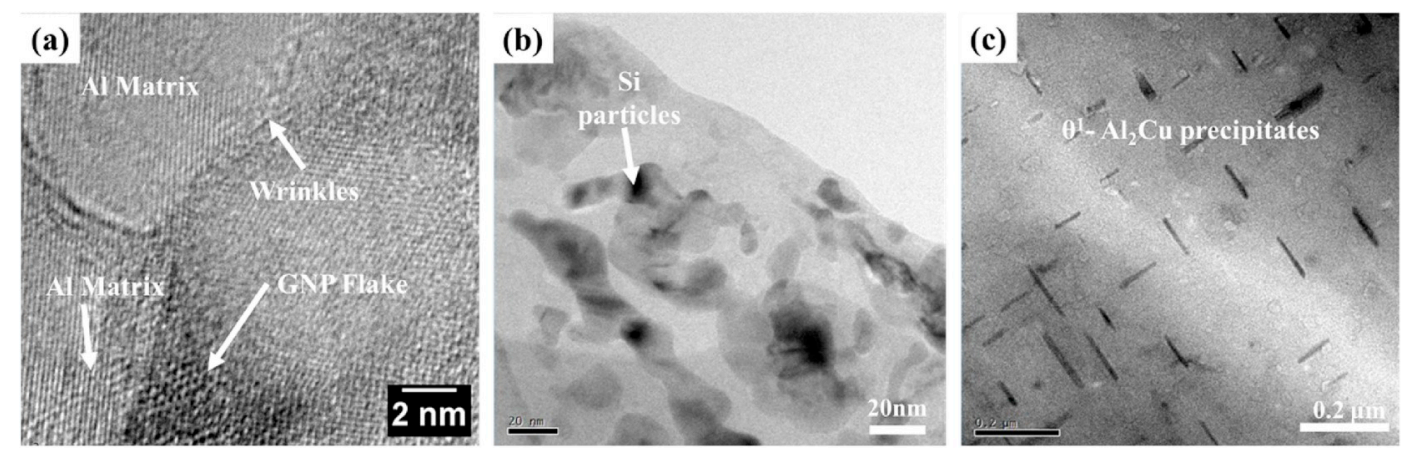

Fig. 10. TEM-BF images of FSP A356 reinforced with GNP showing (a) interface between the matrix and encapsulated GNP flakes (b) nanosize Si particles, and (c) nanosize fine $\mathrm{Al}_{2} \mathrm{Cu}$ precipitates in $\mathrm{Al}$ matrix. 

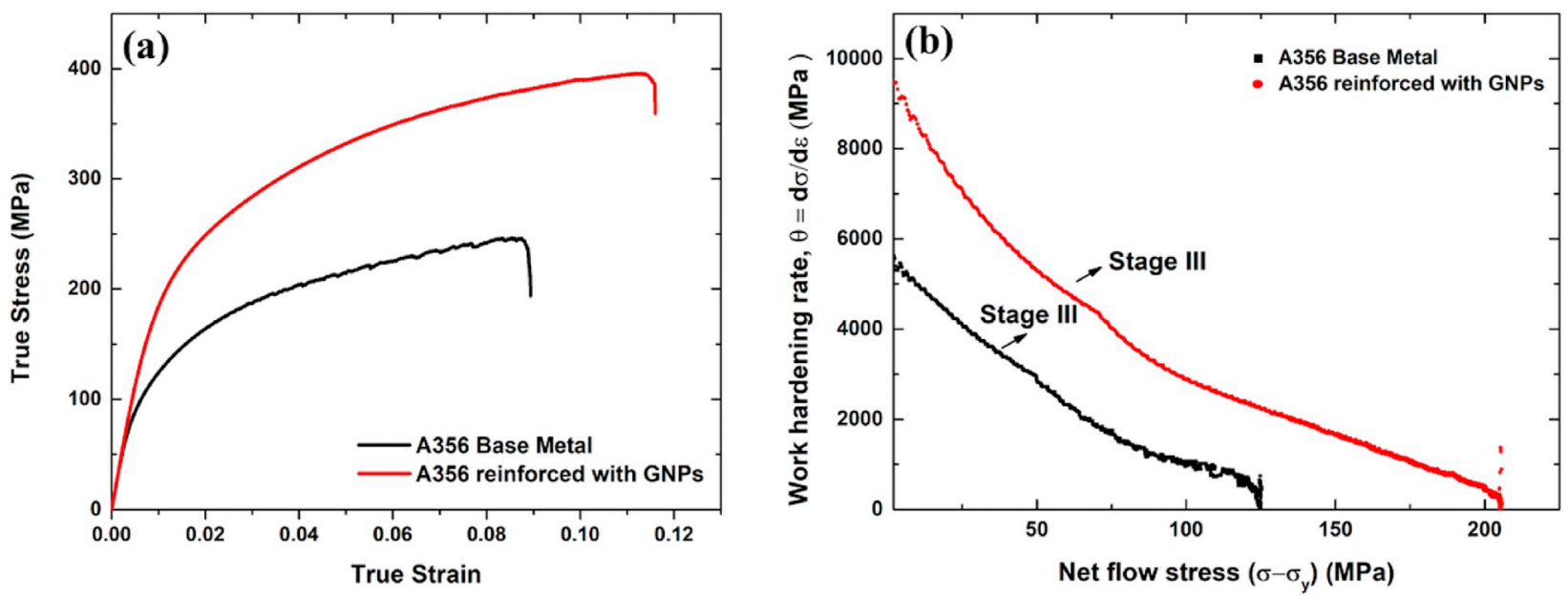

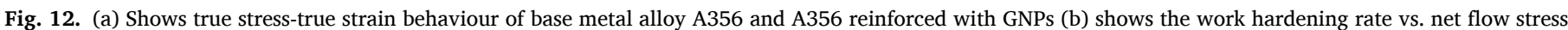
curves of as received the base material (A356) and A356 reinforced with GNPs.

Table 2

A comparison of the yield strength, UTS and percentage elongation of the present study with the values available in the literature.

\begin{tabular}{|c|c|c|c|c|}
\hline References & Material & Yield Strength (MPa) & UTS (MPa) & \% Elongation \\
\hline \multirow[t]{2}{*}{ Present study (Tool rotation- $1200 \mathrm{rpm}$ and traversed with a speed- $15 \mathrm{~mm} / \mathrm{min}$ ) } & Squeeze-cast A356 & $120 \pm 20$ & $238 \pm 15$ & $7.6 \pm 2$ \\
\hline & 6 Pass FSP A356 + GNPs & $190 \pm 13$ & $357 \pm 3$ & $12 \pm 1$ \\
\hline \multirow[t]{2}{*}{ Santella et al., 2005 [42] } & Sand Cast A356 Ingot & $100.37 \pm 1.1$ & $133.37 \pm 7.24$ & $2.03 \pm 0.59$ \\
\hline & FSPed A356 & $87.13 \pm 0.76$ & $173 \pm 0.43$ & $13.03 \pm 0.63$ \\
\hline \multirow[t]{4}{*}{ S. Meenia et al., 2016 [68] (Tool rotation- $800 \mathrm{rpm}$, traverse speeds- $120 \mathrm{~mm} / \mathrm{min}$ ) } & As-cast & 107.44 & 151.91 & 4.79 \\
\hline & 1 Pass FSPed A356 & 109.97 & 181.60 & 21 \\
\hline & 2 pass FSPed A356 & 114.52 & 190.41 & 22.38 \\
\hline & 3 pass FSPed A356 & 127.92 & 200.56 & 36.51 \\
\hline \multirow[t]{2}{*}{ P.R. Guru et al., 2015 [69] (Tool rotation- $800 \mathrm{rpm}$, traverse speeds $-120 \mathrm{~mm} / \mathrm{min}$ ) } & As-cast $\mathrm{Al}-\mathrm{Si} \mathrm{LM} 25$ & 108 & 154 & 4 \\
\hline & FSPed Al-Si LM25 & 121 & 221 & 31 \\
\hline \multirow[t]{3}{*}{ Ma et al., 2008 [70] (Tool rotation- $900 \mathrm{rpm}$, traverse speeds- $203 \mathrm{~mm} / \mathrm{min}$ ) } & As-cast A356 & 132 & 169 & 3 \\
\hline & 1 Pass FSPed A356 & 140 & 232 & 38 \\
\hline & 2 Pass FSPed A356 & 162 & 255 & 34 \\
\hline
\end{tabular}
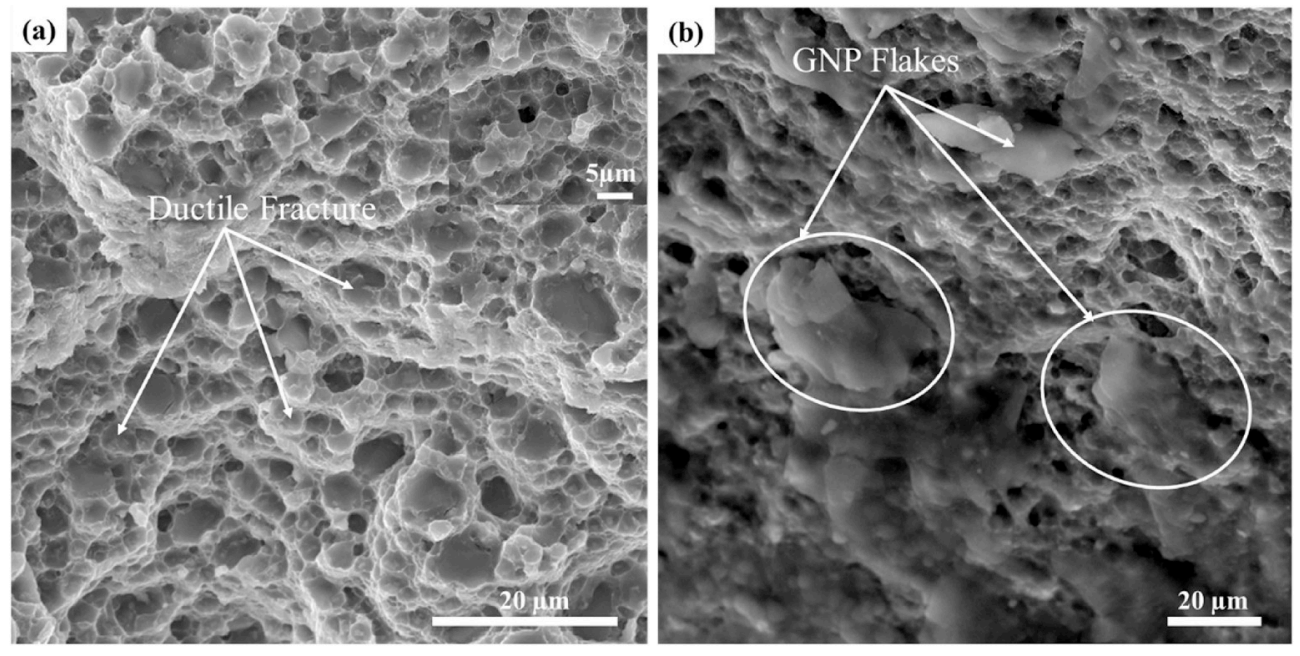

Fig. 13. Shows the SEM image of fractured samples of A356 reinforced with GNPs.

particles and improved properties as compared to sand cast A356 alloy.

2) Compacted graphene nanoparticles physically adhered to the surface of squeeze cast A356 alloy were incorporated in the matrix of refined A356 alloy after Friction Stir Processing.

3) The grain size of aluminum decreased as a result of Friction Stir Processing.
4) The yield strength increased from $120 \mathrm{MPa}$ to $190 \mathrm{MPa}$, ultimate tensile strength increased from $238 \mathrm{MPa}$ to $357 \mathrm{MPa}$ and $12 \%$ improvement in ductility is experimentally for squeeze cast A356graphene FSP composites.

5) The work-hardening rate increased in A356-GNPs composite. 

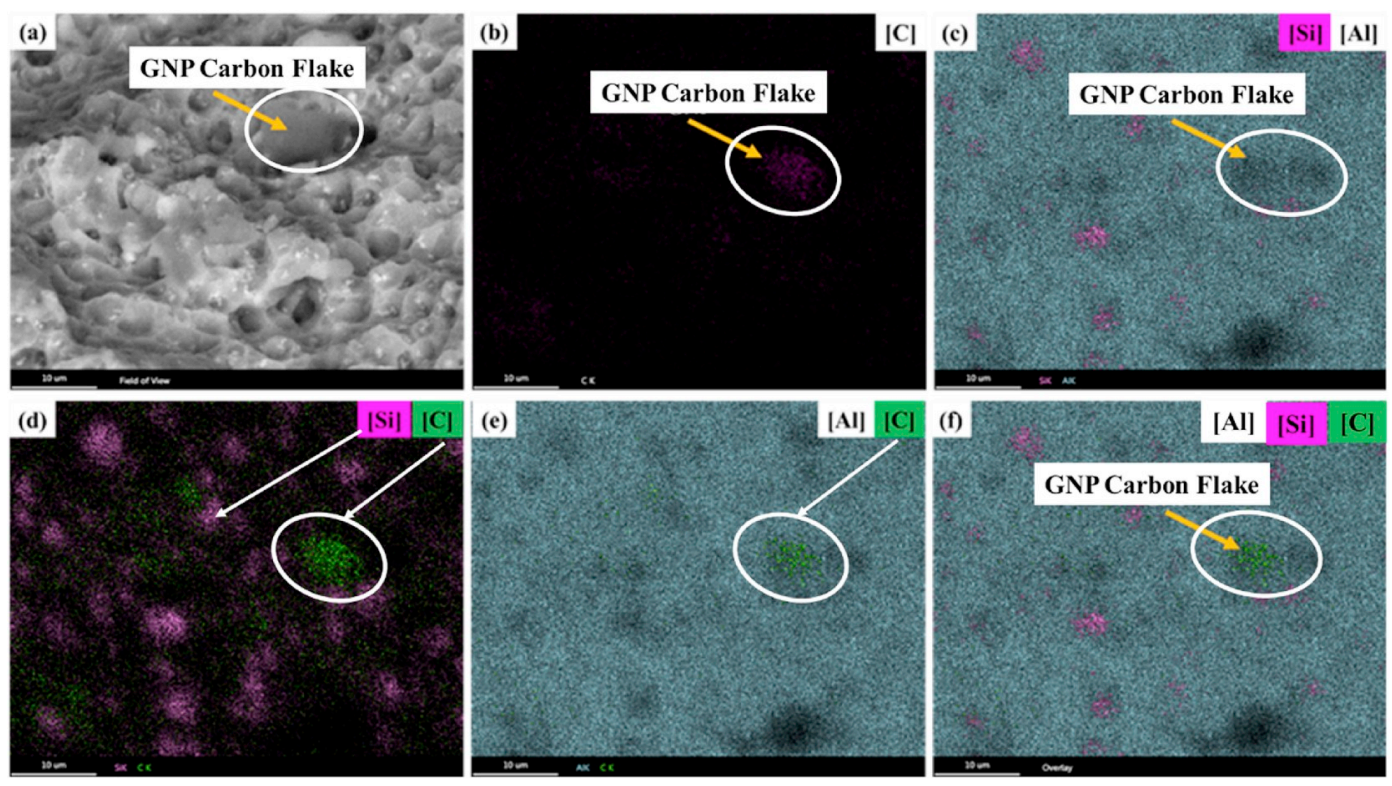

Fig. 14. Shows the EDS mapping of fractured samples of A356 reinforced with GNPs.

\section{Data availability}

The raw/processed data required to reproduce these findings cannot be shared at this time due to legal or ethical reasons and will be available on request.

\section{References}

[1] Y. Hernandez, V. Nicolosi, M. Lotya, F.M. Blighe, Z. Sun, S. De, I. McGovern, B. Holland, M. Byrne, Y.K. Gun'Ko, High-yield production of graphene by liquidphase exfoliation of graphite, Nat. Nanotechnol. 3 (9) (2008) 563.

[2] S. Stankovich, D.A. Dikin, G.H. Dommett, K.M. Kohlhaas, E.J. Zimney, E.A. Stach, R.D. Piner, S.T. Nguyen, R.S. Ruoff, Graphene-based composite materials, Nature 442 (7100) (2006) 282.

[3] S. Stankovich, R.D. Piner, S.T. Nguyen, R.S. Ruoff, Synthesis and exfoliation of isocyanate-treated graphene oxide nanoplatelets, Carbon 44 (15) (2006) 3342-3347.

[4] Y. Xu, H. Bai, G. Lu, C. Li, G. Shi, Flexible graphene films via the filtration of water soluble noncovalent functionalized graphene sheets, J. Am. Chem. Soc. 130 (18) (2008) 5856-5857.

[5] W. Zhao, M. Fang, F. Wu, H. Wu, L. Wang, G. Chen, Preparation of graphene by exfoliation of graphite using wet ball milling, J. Mater. Chem. 20 (28) (2010) 5817-5819.

[6] M.J. Allen, V.C. Tung, R.B. Kaner, Honeycomb carbon: a review of graphene, Chem. Rev. 110 (1) (2009) 132-145.

[7] Y. Zhu, S. Murali, W. Cai, X. Li, J.W. Suk, J.R. Potts, R.S. Ruoff, Graphene and graphene oxide: synthesis, properties, and applications, Adv. Mater. 22 (35) (2010) 3906-3924.

[8] L.-Y. Chen, H. Konishi, A. Fehrenbacher, C. Ma, J.-Q. Xu, H. Choi, H.-F. Xu, F. E. Pfefferkorn, X.-C. Li, Novel nano processing route for bulk graphene nanoplatelets reinforced metal matrix nanocomposites, Scr. Mater. 67 (1) (2012) 29-32.

[9] F. Khodabakhshi, S. Arab, P. Švec, A. Gerlich, Fabrication of a new Al-Mg/ graphene nanocomposite by multi-pass friction-stir processing: dispersion, microstructure, stability, and strengthening, Mater. Char. 132 (2017) 92-107.

[10] L. Yolshina, R. Muradymov, I. Korsun, G. Yakovlev, S. Smirnov, Novel aluminumgraphene and aluminum-graphite metallic composite materials: synthesis and properties, J. Alloy. Comp. 663 (2016) 449-459.

[11] J. Li, Y. Xiong, X. Wang, S. Yan, C. Yang, W. He, J. Chen, S. Wang, X. Zhang, S. Dai, Microstructure and tensile properties of bulk nanostructured aluminum/graphene composites prepared via cryo-milling, Mater. Sci. Eng. A 626 (2015) 400-405.

[12] J. Wang, Z. Li, G. Fan, H. Pan, Z. Chen, D. Zhang, Reinforcement with graphene nanosheets in aluminum matrix composites, Scr. Mater. 66 (8) (2012) 594-597.

[13] S. Shin, H. Choi, J. Shin, D. Bae, Strengthening behavior of few-layered graphene aluminum composites, Carbon 82 (2015) 143-151.

[14] C.-H. Jeon, Y.-H. Jeong, J.-J. Seo, H.N. Tien, S.-T. Hong, Y.-J. Yum, S.-H. Hur, K.J. Lee, Material properties of graphene/aluminum metal matrix composites fabricated by friction stir processing, Int. J. Precis. Eng. Manuf. 15 (6) (2014) 1235-1239.

[15] C.-S. Kim, K. Cho, M.H. Manjili, M. Nezafati, Mechanical performance of particulate-reinforced $\mathrm{Al}$ metal-matrix composites (MMCs) and $\mathrm{Al}$ metal-matrix nano-composites (MMNCs), J. Mater. Sci. 52 (23) (2017) 13319-13349.
[16] A.A. Yar, M. Montazerian, H. Abdizadeh, H. Baharvandi, Microstructure and mechanical properties of aluminum alloy matrix composite reinforced with nanoparticle MgO, J. Alloy. Comp. 484 (1-2) (2009) 400-404.

[17] J. Hemanth, Development and property evaluation of aluminum alloy reinforced with nano- $\mathrm{ZrO}_{2}$ metal matrix composites (NMMCs), Mater. Sci. Eng. A 507 (1-2) (2009) 110-113.

[18] M. Li, K. Ma, L. Jiang, H. Yang, E.J. Lavernia, L. Zhang, J.M. Schoenung, Synthesis and mechanical behavior of nanostructured Al 5083/n-TiB2 metal matrix composites, Mater. Sci. Eng. A 656 (2016) 241-248.

[19] S.R. Bakshi, D. Lahiri, A. Agarwal, Carbon nanotube reinforced metal matrix composites-a review, Int. Mater. Rev. 55 (1) (2010) 41-64.

[20] B. Schultz, J. Ferguson, P. Rohatgi, Microstructure and hardness of $\mathrm{Al}_{2} \mathrm{O}_{3}$ nanoparticle reinforced $\mathrm{Al}-\mathrm{Mg}$ composites fabricated by reactive wetting and stir mixing, Mater. Sci. Eng. A 530 (2011) 87-97.

[21] J. Lan, Y. Yang, X. Li, Microstructure and microhardness of SiC nanoparticles reinforced magnesium composites fabricated by the ultrasonic method, Mater. Sci. Eng. A 386 (1-2) (2004) 284-290.

[22] Y. Yang, J. Lan, X. Li, Study on bulk aluminum matrix nano-composite fabricated by ultrasonic dispersion of nano-sized $\mathrm{SiC}$ particles in molten aluminum alloy, Mater. Sci. Eng. A 380 (1-2) (2004) 378-383.

[23] R. George, K. Kashyap, R. Rahul, S. Yamdagni, Strengthening in carbon nanotube/ aluminum (CNT/Al) composites, Scr. Mater. 53 (10) (2005) 1159-1163.

[24] A.D. Moghadam, E. Omrani, H. Lopez, L. Zhou, Y. Sohn, P.K. Rohatgi, Strengthening in hybrid alumina-titanium diboride aluminum matrix composites synthesized by ultrasonic assisted reactive mechanical mixing, Mater. Sci. Eng. A 702 (2017) 312-321.

[25] H. Su, W. Gao, Z. Feng, Z. Lu, Processing, microstructure and tensile properties of nano-sized Al2O3 particle reinforced aluminum matrix composites, Mater. Des. 36 (2012) 590-596, 1980-2015.

[26] D.R. Kongshaug, J. Ferguson, B.F. Schultz, P.K. Rohatgi, Reactive stir mixing of $\mathrm{Al}-\mathrm{Mg} / \mathrm{Al} 2 \mathrm{O} 3 \mathrm{np}$ metal matrix nanocomposites: effects of $\mathrm{Mg}$ and reinforcement concentration and method of reinforcement incorporation, J. Mater. Sci. 49 (5) (2014) 2106-2116.

[27] A. Kumar, R. Raj, S.V. Kailas, A novel in-situ polymer derived nano ceramic MMC by friction stir processing, Mater. Des. 85 (2015) 626-634.

[28] E.L.R. John Gilbert Kaufman, Aluminum Alloy Castings: Properties, Processes, and Applications, ASM International, 2004.

[29] D. Zhang, L. Zheng, The quench sensitivity of cast Al-7 wt pet Si-0.4 wt pct Mg alloy, Metall. Mater. Trans. A 27 (12) (1996) 3983-3991.

[30] Y. Yu, P. Song, S. Kim, J. Lee, Possibility of improving tensile strength of semi-solid processed A356 alloy by a post heat treatment at an extremely high temperature, Scr. Mater. 7 (41) (1999) 767-771.

[31] T. Din, J. Campbell, High strength aerospace aluminium casting alloys: a comparative study, Mater. Sci. Technol. 12 (8) (1996) 644-650.

[32] K. Oswalt, M. Misra, Dendrite arm spacing (DAS): a nondestructive test to evaluate tensile properties of premium-quality aluminum alloy (Al-Si-Mg) castings, Int. Cast Met. J. 6 (1) (1981) 23-40.

[33] K. Radhakrishna, S. Seshan, M. Seshadri, Dendrite arm spacing in aluminum alloy castings, AFS Transactions 88 (1980) 695-702.

[34] B. Closset, J. Gruzleski, Structure and properties of hypoeutectic Al-Si-Mg alloys modified with pure strontium, Metallurgical Transactions A 13 (6) (1982) 945-951.

[35] M. Surappa, Effect of macro-porosity on the strength and ductility of cast al-7 si-0.3 mg alloy, Scr. Metall. 20 (9) (1986) 1281-1286. 
[36] G. Gustafsson, T. Thorvaldsson, G. Dunlop, The influence of Fe and Cr on the microstructure of cast Al-Si-Mg alloys, Metallurgical Transactions A 17 (1) (1986) 45-52.

[37] C. Caceres, J. Griffiths, Damage by the cracking of silicon particles in an Al-7Si-0.4 Mg casting alloy, Acta Mater. 44 (1) (1996) 25-33.

[38] G. Atxaga, A. Pelayo, A. Irisarri, Effect of microstructure on fatigue behaviour of cast Al-7Si-Mg alloy, Mater. Sci. Technol. 17 (4) (2001) 446-450.

[39] M.E. Seniw, J.G. Conley, M.E. Fine, The effect of microscopic inclusion locations and silicon segregation on fatigue lifetimes of aluminum alloy A356 castings, Mater. Sci. Eng. A 285 (1-2) (2000) 43-48.

[40] B. Zhang, D. Poirier, W. Chen, Microstructural effects on high-cycle fatigue-crack initiation in A356. 2 casting alloy, Metall. Mater. Trans. A 30 (10) (1999) 2659-2666.

[41] S. Kumai, J. Hu, Y. Higo, S. Nunomura, Effects of dendrite cell size and particle distribution on the near-threshold fatigue crack growth behaviour of cast Al-SiCp composites, Acta Mater. 44 (6) (1996) 2249-2257.

[42] M. Santella, T. Engstrom, D. Storjohann, T.-Y. Pan, Effects of friction stir processing on mechanical properties of the cast aluminum alloys A319 and A356, Scr. Mater. 53 (2) (2005) 201-206.

[43] Z. Ma, R.S. Mishra, M.W. Mahoney, Superplasticity in cast A356 induced via friction stir processing, Scr. Mater. 50 (7) (2004) 931-935.

[44] V. Vishnu Namboodiri, Anirudhan Pottirayil, P. Ajay Kumar, Satish V. Kailas, Wear behavior of friction stir processed NAB alloys in marine environment, Tribol. Online 13 (3) (2018) 75-80.

[45] H. Madhu, P.A. Kumar, C.S. Perugu, S.V. Kailas, Microstructure and mechanical properties of friction stir process derived $\mathrm{Al}-\mathrm{TiO}_{2}$ nanocomposite, J. Mater. Eng. Perform. 1-9.

[46] R.S. Mishra, M.W. Mahoney, Friction stir processing: a new grain refinement technique to achieve high strain rate superplasticity in commercial alloys, Materials Science Forum, Trans Tech Publ (2001) 507-514.

[47] P.B. Berbon, W.H. Bingel, R.S. Mishra, C.C. Bampton, M.W. Mahoney, Friction stir processing: a tool to homogenize nanocomposite aluminum alloys, Scr. Mater. 44 (1) (2001) 61-66.

[48] R.S. Mishra, Z. Ma, I. Charit, Friction stir processing: a novel technique for fabrication of surface composite, Mater. Sci. Eng. A 341 (1) (2003) 307-310.

[49] H. Liu, Y. Hu, Y. Zhao, H. Fujii, Microstructure and mechanical properties of friction stir welded AC4A+ 30 vol.\% SiCp composite, Mater. Des. 65 (2015) 395-400, 1980-2015.

[50] Y.X. Gan, D. Solomon, M. Reinbolt, Friction stir processing of particle reinforced composite materials, Materials 3 (1) (2010) 329-350.

[51] W. Wang, Q.-y. Shi, P. Liu, H.-k. Li, T. Li, A novel way to produce bulk SiCp reinforced aluminum metal matrix composites by friction stir processing, J. Mater. Process. Technol. 209 (4) (2009) 2099-2103.

[52] R. Srinivasu, A.S. Rao, G.M. Reddy, K.S. Rao, Friction stir surfacing of cast A356 aluminum-silicon alloy with boron carbide and molybdenum disulfide powders, Defence Technology 11 (2) (2015) 140-146.

[53] M. Barmouz, P. Asadi, M.B. Givi, M. Taherishargh, Investigation of mechanical properties of $\mathrm{Cu} / \mathrm{SiC}$ composite fabricated by FSP: effect of SiC particles' size and volume fraction, Mater. Sci. Eng. A 528 (3) (2011) 1740-1749.

[54] A. Kumar, D. Yadav, C.S. Perugu, S.V. Kailas, Influence of particulate reinforcement on microstructure evolution and tensile properties of in-situ polymer derived MMC by friction stir processing, Mater. Des. 113 (2017) 99-108.
[55] S. Aktarer, D. Sekban, H. Yanar, G. Purçek, Effect of friction stir processing on tribological properties of Al-Si alloys, in: IOP Conference Series: Materials Science and Engineering, IOP Publishing, 2017, 012061.

[56] S. Dixit, A. Mahata, D.R. Mahapatra, S.V. Kailas, K. Chattopadhyay, Multi-layer graphene reinforced aluminum - manufacturing of high strength composite by friction stir alloying, Compos. B Eng. 136 (Supplement C) (2018) 63-71.

[57] Z. Ma, S. Sharma, R. Mishra, Effect of friction stir processing on the microstructure of cast A356 aluminum, Mater. Sci. Eng. A 433 (1) (2006) 269-278.

[58] W.B. Lee, Y. Yeon, S. Jung, The improvement of mechanical properties of frictionstir-welded A356 Al alloy, Mater. Sci. Eng. A 355 (1-2) (2003) 154-159.

[59] Z. Zhang, Z. Liu, B. Xiao, D. Ni, Z. Ma, High-efficiency dispersal and strengthening of graphene-reinforced aluminum alloy composites fabricated by powder metallurgy combined with friction stir processing, Carbon 135 (2018) 215-223.

[60] K.R. Cardoso, M. Munoz-Morris, K.V. León, D.G. Morris, Room and hightemperature ECAP processing of Al-10\% Si alloy, Mater. Sci. Eng. A 587 (2013) 387-396.

[61] D.C. Elias, R.R. Nair, T. Mohiuddin, S. Morozov, P. Blake, M. Halsall, A.C. Ferrari, D. Boukhvalov, M. Katsnelson, A. Geim, Control of graphene's properties by reversible hydrogenation: evidence for graphane, Science 323 (5914) (2009) 610-613.

[62] F. Tuinstra, J.L. Koenig, Raman spectrum of graphite, J. Chem. Phys. 53 (3) (1970) 1126-1130.

[63] A. Kaniyoor, S. Ramaprabhu, A Raman spectroscopic investigation of graphite oxide derived graphene, AIP Adv. 2 (3) (2012), 032183.

[64] U. Mogera, N. Kurra, D. Radhakrishnan, C. Narayana, G.U. Kulkarni, Low cost, rapid synthesis of graphene on Ni: an efficient barrier for corrosion and thermal oxidation, Carbon 78 (2014) 384-391.

[65] V. Leon, M. Quintana, M.A. Herrero, J.L. Fierro, A. de la Hoz, M. Prato, E. Vazquez, Few-layer graphenes from ball-milling of graphite with melamine, Chem. Commun. 47 (39) (2011) 10936-10938.

[66] L. Cançado, K. Takai, T. Enoki, M. Endo, Y. Kim, H. Mizusaki, A. Jorio, L. Coelho, R. Magalhaes-Paniago, M. Pimenta, General equation for the determination of the crystallite size La of nanographite by Raman spectroscopy, Appl. Phys. Lett. 88 (16) (2006) 163106.

[67] L.G. Cançado, A. Jorio, E.M. Ferreira, F. Stavale, C. Achete, R. Capaz, M. Moutinho, A. Lombardo, T. Kulmala, A.C. Ferrari, Quantifying defects in graphene via Raman spectroscopy at different excitation energies, Nano Lett. 11 (8) (2011) 3190-3196.

[68] S. Meenia, S. Babu, R. Immanuel, S. Panigrahi, G.J. Ram, Particle refinement and fine-grain formation leading to enhanced mechanical behavior in a hypo-eutectic Al-Si alloy subjected to multi-pass friction stir processing, Mater. Char. 113 (2016) $134-143$.

[69] P. Guru, F. Khan, S. Panigrahi, G.J. Ram, Enhancing strength, ductility and machinability of an Al-Si cast alloy by friction stir processing, J. Manuf. Process. 18 (2015) 67-74.

[70] Z. Ma, A. Pilchak, M. Juhas, J. Williams, Microstructural refinement and property enhancement of cast light alloys via friction stir processing, Scr. Mater. 58 (5) (2008) 361-366.

[71] W.-m. Jiang, Z.-t. Fan, D.-j. Liu, Microstructure, tensile properties and fractography of A356 alloy under as-cast and T6 obtained with expendable pattern shell casting process, Trans. Nonferrous Metals Soc. China 22 (2012) s7-s13.

[72] U. Kocks, Laws for work-hardening and low-temperature creep, J. Eng. Mater. Technol. 98 (1) (1976) 76-85. 